\title{
TECHNOLOGY IN PHARMACY EDUCATION
}

\section{Use of Twitter to Encourage Interaction in a Multi-campus Pharmacy Management Course}

\author{
Brent I. Fox, PharmD, PhD, and Ranjani Varadarajan, MS \\ Auburn University Harrison School of Pharmacy \\ Submitted January 5, 2011; accepted April 1, 2011; published June 10, 2011.
}

Objective. To implement and assess the effectiveness of using Twitter to encourage interaction between faculty members, guests, and students in a pharmacy management course taught simultaneously on 2 campuses.

Design. Students were required to tweet a minimum of 10 times over several class sessions. The course instructor and guest professionals also participated.

Assessment. More than eighteen hundred tweets were made by students, guests, and the instructor. Students tweeted most frequently with each other and found value in reading each others' tweets. One hundred thirty-one students completed an optional evaluation survey. Seventy-one percent indicated that Twitter was distracting, $69 \%$ believed it prevented note taking, and more than $80 \%$ indicated that it facilitated class participation and allowed an opportunity to voice opinions.

Conclusion. Educators who wish to use Twitter in pharmacy courses must balance the potentially positive aspects of the technology, such as increased interaction among students, with potentially negative aspects, such as the interruptive nature of Twitter use and the large volume of tweets generated by a class assignment.

Keywords: Twitter, interaction, social networking, class participation

\section{INTRODUCTION}

Today's students are entering pharmacy school with skills, experiences, and expectations that are different from those of any students educators have previously encountered. ${ }^{1}$ Known by several labels including the "Millennials," these students were born in or after 1982 and are accustomed to hectic schedules, using information technology and multimedia extensively, and participating in group activities. They prefer learning environments that use technology, active learning, teamwork, and multitasking. ${ }^{1-3}$ Millennials consider technology to be a natural part of their environment - a perception resulting in part from their extensive use of the Internet for educational and personal pursuits.

These characteristics of the Millennial students have important implications for pharmacy educators. Are we using technology in innovative ways that allows active learning, teamwork, and multitasking? Authors have previously described the use of Web 2.0 tools as potential resources to engage today's students. ${ }^{4}$ Blogs are Web-based journals with an unlimited amount of space where bloggers express their thoughts in textual form and blog visitors have the

Corresponding Author: Brent Fox, 207 Dunstan Hall, Auburn University, AL 36849. Tel: 334-844-5152. Fax: 334-844-8307. E-mail: foxbren@auburn.edu ability to provide comments. Microblogs are similar to blogs except that they have a defined amount of space for writing.

Twitter (www.twitter.com) is the most popular microblog, with $17 \%$ of Millennials who attend or have attended college having posted a message on Twitter. ${ }^{3}$ Twitter users post messages ("tweets") of 140 characters or less that are read by other users who have chosen to "follow" the person who posted the tweet. Followers can then "retweet" messages that they receive, posting it for their followers to see (and to potentially retweet as well). Tweets also can be directed to someone using an @tweet where the tweet includes “@username," and the username is the intended recipient's Twitter name. Twitter users also can send private, direct tweets similar to instant messages. Lists can be created to collect the tweets of individuals who share common interests, expertise, and other characteristics. Twitter users also can elect to make their tweets private, viewable only to individuals who they have authorized. Lists can be public or private as well.

Literature on Twitter (and other Web 2.0 applications) used in education is in its infancy. ${ }^{5-10}$ Although difficult to quantify, there appears to be more literature addressing Twitter use in K-12 settings than in higher education. In health and medicine, Twitter has received attention for a variety of uses including continuing education, marketing and networking, infodemiologic data 


\section{American Journal of Pharmaceutical Education 2011; 75 (5) Article 88.}

collection (collecting data using an electronic medium, usually the Internet), public health promotion, and sharing antibiotic and other health-related information. ${ }^{11-17}$ More information about Twitter use in education and medicine can be found in blogs and online news resources. Generally, these reports describe experiences (good and bad) with using Twitter in novel ways.

This paper describes experiences and lessons learned from a class activity that incorporated Twitter as a communication tool among students, the instructor, and invited guests. The goals of the activity were to (1) introduce students to Twitter use during their professional education, (2) provide students an opportunity to interact with each other, the instructor, and guests during class, and (3) determine student perceptions of Twitter as a class tool. The goal of this manuscript is to inform instructors of potential issues to consider when implementing Twitter in their classroom. The publication of the results of this activity was approved by the Auburn University Institutional Review Board.

\section{DESIGN}

In the P2 year at Auburn, students are enrolled in a 2-semester course sequence entitled, "Pharmacy Practice Development, Management, and Evaluation." The spring 2010 semester was composed of 3 units: marketing (8 weeks), financial (4 weeks), and information technology ( 4 weeks). The course met twice weekly for 1 hour and 15 minutes. The course was team taught by 3 faculty members with guest instructors included periodically. Four graduate teaching assistants were assigned to the course, with the fourth only helping with examination proctoring. The course was worth a total of 1000 points. The Twitter activity, which occurred during the information technology unit, was worth 20 points ( $2 \%$ of their grade). Students also were given an opportunity to earn 5 bonus points by completing an online, anonymous evaluation of the Twitter activity.

One-hundred forty-three students were enrolled in the course; 119 in Auburn and 24 at the satellite campus in Mobile, AL. Course requirements were the same across campuses. The school required students to purchase a laptop computer, and school policy stated that students were required to bring their computers to any course that included video conferencing. The class was taught from Auburn using live, synchronous video conferencing connecting the 2 campuses. ${ }^{18}$

\section{Framing Interaction}

The Twitter activity was implemented out of a desire to give students a new opportunity to interact during class with each other, the instructor, and invited guests. Inter- action among students and instructors in distance education settings has received considerable attention. Specifically, interaction has been classified into 5 types: learner-content, learner-instructor, learner-learner, learner-interface, and vicarious interaction. ${ }^{19-21}$ Learner-content interaction has been described as the "internal didactic conversation" in which a learner intellectually interacts with content, resulting in changes in the learner's understanding, perspective, and mind. Learner-instructor interaction occurs between the student and the individual who prepared the material or is an expert in it. Learner-learner interaction occurs between students, alone or in groups, and is independent of the presence of an instructor. ${ }^{20}$ Learner-interface interaction focuses on the importance of technology as an intermediary between the learner and the content, instructor, or other learners, and is especially important when the learner is not familiar with the technology, thus impeding other types of interaction from occurring. ${ }^{19}$ Vicarious interaction occurs when a learner actively observes and processes interactions between other learners or between learners and the instructor. ${ }^{21}$

While the activity was not designed to specifically test the interaction model, the model provides a framework for the students' experiences. Specifically, tweets were used as indicators of 3 of the 5 types of interaction. Learner-instructor interaction was indicated by tweets occurring between the students and the instructor and/or invited guests. Learner-learner interaction was indicated by student@ @tweets to other students and by retweets of other students' tweets. Learner-content interaction was indicated by the tweets that did not fit in either the learner-instructor or learner-learner categories. Depending on the content of the tweet, learner-content interaction also could be found in other tweets. For example, an @ tweet to a fellow student containing a question about the day's reading could indicate learner-learner and learner-content interaction. For this study, learner-learner and learner-instructor tweets were not examined to determine if they also could be classified as learner-content. The other types of interaction (learner-interface and vicarious) were indicated in the students' evaluation of the activity. The evaluation also provided additional insight into learner-learner and learner-instructor interaction.

\section{Preparation}

As described above, Twitter users "follow" each other to see tweets as they are posted. This is accomplished by locating a user's Twitter account (eg, www.twitter. com/@Brent_Fox) and clicking the "follow" button. For the purpose of the class activity, the instructor, graduate students, PharmD students, and guests needed to follow all tweets from the class. The original plan was to use 


\section{American Journal of Pharmaceutical Education 2011; 75 (5) Article 88.}

a hashtag to allow everyone to follow all tweets. (A hashtag is a keyword immediately preceded by the pound or hash symbol, \#. Hashtags were developed by Twitter users as a way to add metadata to tweets. ${ }^{22}$ ) Hashtags can be included anywhere in a tweet and are used extensively to indicate/designate that tweets are related to a specific topic. The course instructor created a hashtag (\#auhsop) for the course and required that it be included on all student, guest, and instructor tweets. Everyone participating in the activity (including guests) was instructed to follow tweets by using the Twitter search feature (http:// search.twitter.com) to locate all tweets that included "\#auhsop". Additionally, students were informed about the Twitterfall.com service that also searched for hashtags, displaying them in a waterfall-like manner.

Students were given a document detailing the instructions and requirements for the activity during the first class on information technology. The activity and accompanying file were reviewed in class along with general Twitter usage, which was demonstrated using a volunteer from the class. To comply with the Family Educational Rights and Privacy Act's (FERPA) requirements for student privacy, a locally developed application (SmartAlias, https://sa.auburn.edu/index.php?about=1) assigned an anonymous Twitter username for each student. Only the instructor and graduate students had access to the file created by SmartAlias that linked students with their anonymous Twitter usernames. Time was allotted in class to create Twitter accounts and review the instructions. Students were instructed to experiment with Twitter and were told that, beginning with the next class meeting ("Day 1"), their tweets would be recorded for purposes of the assignment. Graduate students used the tweets from the introduction day as an opportunity to test their procedures for following and recording tweets.

Students were required to post at least 2 tweets during class from a minimum of 5 of the information technology sessions (a minimum of 10 tweets for 20 points). They were instructed to tweet as many times as they wanted as long as they remained on topic. Examples of appropriate and inappropriate tweets were provided. Any tweets deemed inappropriate resulted in forfeiture of all points for the activity. Students were instructed to include the hashtag on all tweets.

Retweets, @tweets, and tweets outside of class were encouraged. Students were informed that their tweets might be shown during class for discussion purposes. The instructor invited 7 professional colleagues (including 2 faculty members from other PharmD programs) to tweet with the students using the designated hashtag. Students were informed that they might see tweets from these guests. Students also were told that a transcript of tweets might be created for publication. Additional Twitter tips were provided including how to share pictures, Web addresses, and third-party tools for following "conversations" in Twitter.

Graduate teaching assistants were responsible for creating an archive of all tweets, tabulating the number of tweets by each student, and identifying inappropriate tweets. Due to experiences during the introduction day, an alternative method of following class tweets than originally planned was implemented. Students and the graduate assistants commented that it was cumbersome to use the search feature to follow all tweets. Additionally, students reported that they often forgot to include the hashtag in their tweets, making Twitterfall.com useless for retrieving/following tweets. The alternate method identified was to use a list. Twitter Lists allow users to organize other users into lists (groups). By following a list, the user then sees all tweets from everyone in the list. ${ }^{23} \mathrm{~A}$ list ("hsop-spr2010") was created for the class, all students were added to the list by the instructor, and all students were subsequently instructed to follow the list. By creating a list that all students, graduate assistants, and guests could follow, it was not necessary to use a hashtag or search function to follow all tweets.

\section{EVALUATION AND ASSESSMENT Twitter Posts}

Students posted 1775 tweets during the 6 days in which their posts were being recorded (Figure 1). Three students posted less than 10 tweets. No inappropriate tweets were identified. Students tweeted frequently, with a low of 99 on the last day and a high of 474 on the second day (average of 295 tweets/day and approximately 12 tweets/student). Tweets by guests and the instructor made up a small number of the total tweets. Figure 2 presents student tweets by type. The majority of student tweets were standard, followed by @tweets, which ranged from $8 \%$ to $27 \%$ of all tweets for the day. Students retweeted once on day 1 and twice on days 2 and 3. Guests tweeted only on days 1,3 , and 5 , and the instructor tweeted only on day 6 when there was a guest lecturer (Figure 3). Although the frequency of tweets was lower for guests and the instructor, when they did tweet, their use of @ tweets and retweets was high (67\% to 100\% combined @tweets and retweets).

\section{Student Survey}

At the conclusion of the semester, all students received an invitation to complete an optional, anonymous survey in Blackboard for 5 bonus points toward their 1000-point total for the course. The instructor was able 


\section{American Journal of Pharmaceutical Education 2011; 75 (5) Article 88.}

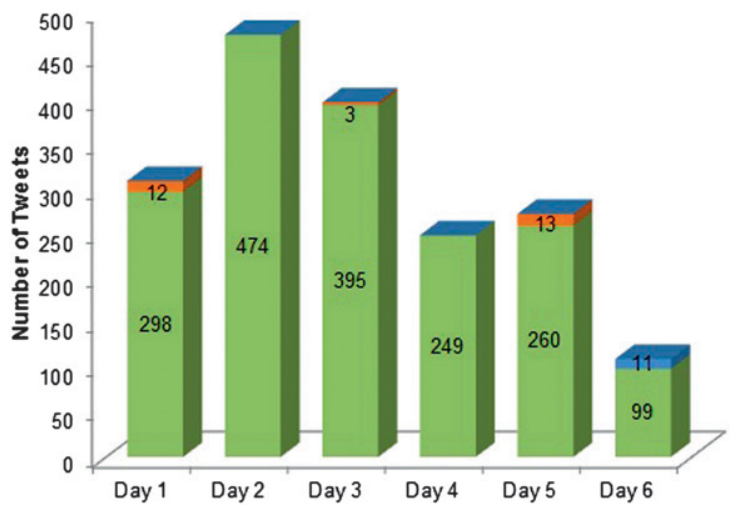

Figure 1 . Tweets by day and user.

to retrieve a list of all students who completed the survey instrument from Blackboard, but Blackboard did not link survey answers with student usernames. The survey instrument was created by the author (B.I.F) as a mechanism to determine students' perceptions of their experiences using Twitter with the intent of using survey responses to guide instructors in modifying the activity if it was repeated in future semesters. The goal of the survey was to determine the successful and unsuccessful aspects of the activity, from the students' perspectives. The survey instrument was reviewed for face validity by 2 pharmacy faculty members. Twelve of the survey questions focused on students' perceptions of the amount of work the activity required, the distractive nature of the activity, the activity's facilitation of idea and opinion sharing, the usefulness of guest and instructor tweets, student concerns about privacy, students' desire to use Twitter in the future, and general benefits and limitations of the activity. Responses were multiple choice or ranked using a Likerttype scale, and reported as frequencies.

The 2 remaining survey questions asked students to describe a benefit and limitation of the activity. In reviewing responses to these open-ended questions, the author read each one and then created categories based on response themes until all responses were categorized. Some

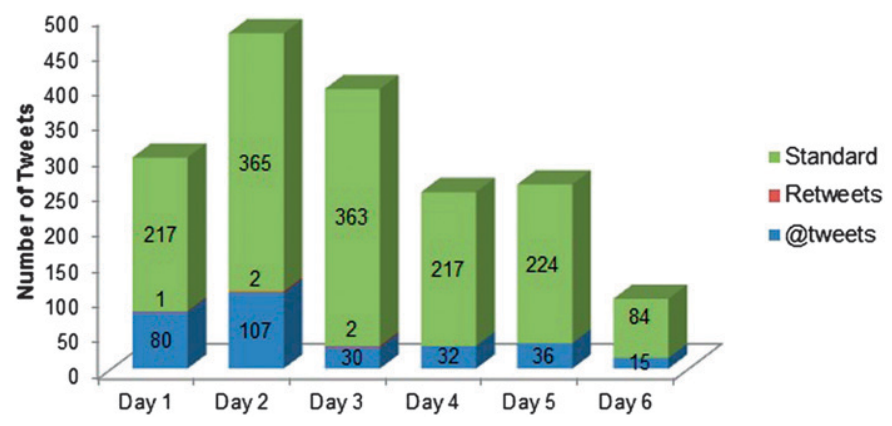

Figure 2. Student tweets by type.

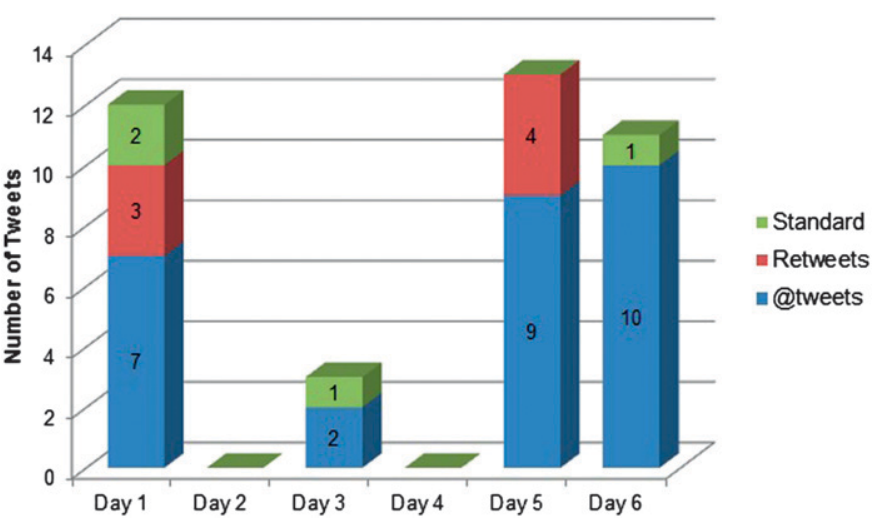

Figure 3. Guest (days 1, 3 and 5) and instructor (day 6) tweets by type.

responses contained more than 1 theme and were subsequently categorized in multiple categories. A pharmacy faculty colleague then reviewed all responses and categories for agreement. If disagreement existed, discussions ensued to determine the best, agreed-upon categorization.

The survey instrument was completed by 131 students ( $n=143,92 \%$ response rate). When asked whether the required number of tweets for the number of points available was too low, about right, or too high, 1 student indicated too low, $119(91 \%)$ indicated about right, and $11(8 \%)$ indicated too high. Table 1 presents students responses for 5 additional survey questions. A large percentage of students indicated that Twitter distracted them from course discussions (71\%) and prevented them from taking notes as thoroughly as they wanted (69\%). However, $82 \%$ indicated that Twitter facilitated sharing of ideas among the class and $81 \%$ indicated that it allowed them to express an opinion when they would not have otherwise done so in class. Ninety-percent of respondents were not concerned about protecting their privacy when using Twitter in class.

For the 2 open-ended questions, 97 students listed benefits and 105 listed limitations of the activity. Table 2 presents the categories, number of statements per category, and example statements for both positive and negative comments.

\section{Assessment of Twitter as an Interaction Tool}

The students' survey responses and the 1814 tweets by the students (1775), guests (28), and instructor (11) were assessed to determine Twitter's utility/usefulness as an interaction tool based on the 5 types of interaction defined above.

Learner-Instructor. Students posted $3 @$ tweets to the instructor, no@tweets to guests, and no retweets of guest or instructor tweets. Guests posted $18 @$ tweets to students and 7 retweets of student tweets. The instructor 


\section{American Journal of Pharmaceutical Education 2011; 75 (5) Article 88.}

Table 1. Student Responses to Twitter Survey $(n=131)$

\begin{tabular}{|c|c|c|c|c|}
\hline & $\begin{array}{c}\text { Strongly } \\
\text { Disagree, \% }\end{array}$ & Disagree, \% & Agree, \% & $\begin{array}{l}\text { Strongly } \\
\text { Agree, \% }\end{array}$ \\
\hline Q1. The use of Twitter distracted me from course discussions. & 8 & 21 & 40 & 31 \\
\hline Q3. The use of Twitter facilitated sharing of ideas among the class. & 5 & 13 & 61 & 21 \\
\hline $\begin{array}{l}\text { Q4. I learned something about the course content from reading } \\
\text { my classmates' tweets. }\end{array}$ & 9 & 30 & 52 & 9 \\
\hline $\begin{array}{l}\text { Q5. The use of Twitter allowed me to express my opinion when } \\
\text { I would not otherwise have expressed it in class. }\end{array}$ & 7 & 12 & 56 & 25 \\
\hline
\end{tabular}

tweeted a total of 11 times, posting $10 @$ tweets to students and no retweets (Figure 3). These results suggest that student-initiated interaction with guests and the instructor occurred infrequently. However, when they tweeted, guests and the instructor initiated interaction with students frequently.

Learner-Learner. Students posted 297 @tweets to other students, representing $17 \%$ of all student tweets.
Students retweeted 5 times. Nearly 1 in 5 student tweets represented potential interaction between students.

Learner-Content. The remaining 1470 student tweets ( $82 \%$ of total) were classified as standard, meaning that the student tweeted a comment or question about the content for that day's class.

Learner-Interface. Seventy-seven percent of survey respondents indicated never using Twitter before.

Table 2. Students' Positive and Negative Perceptions About Twitter Use in Class

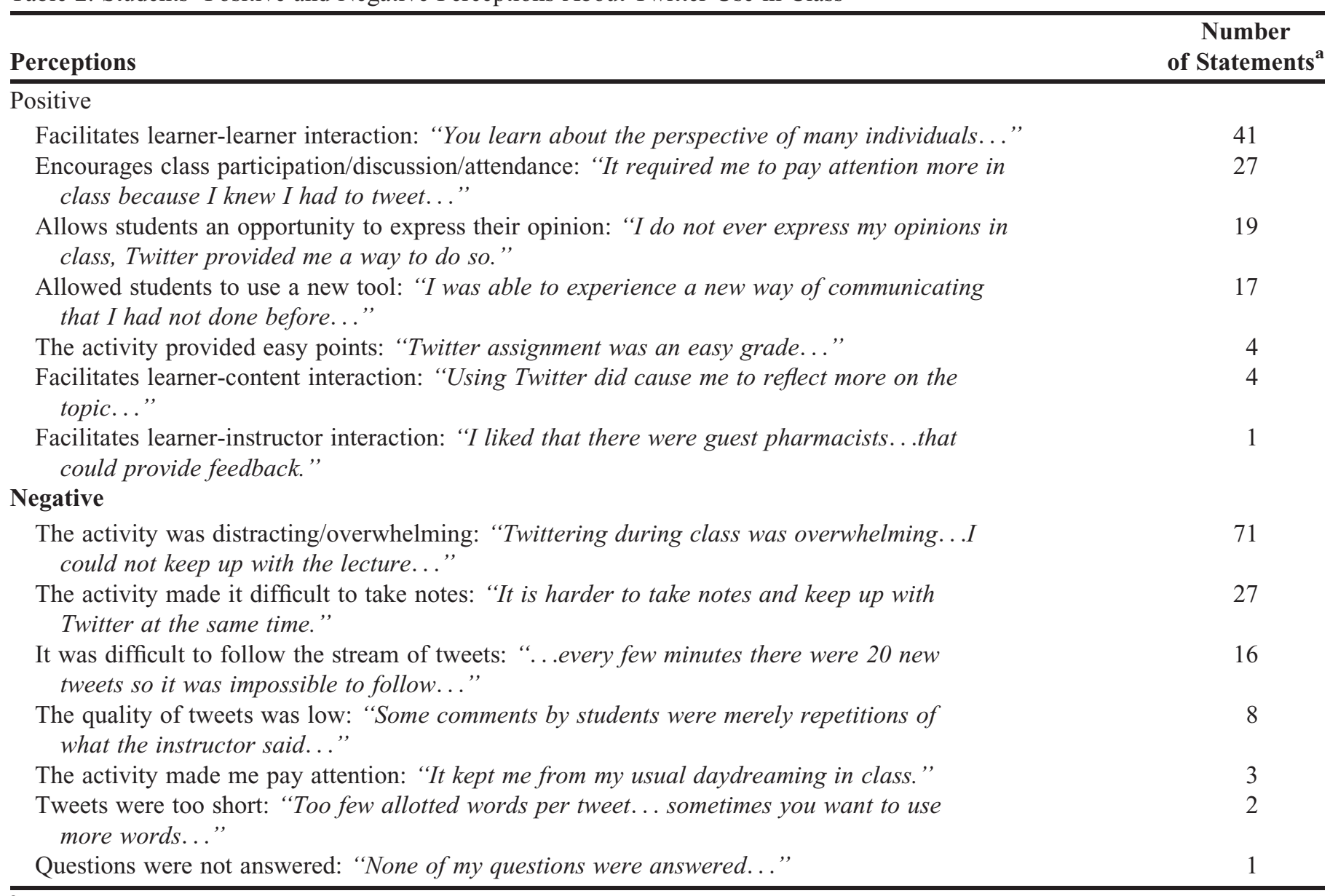

${ }^{a}$ A single comment could contain multiple statements. 


\section{American Journal of Pharmaceutical Education 2011; 75 (5) Article 88.}

Twenty-five students (19\%) indicated they would like to have had more instruction on how to use Twitter for class. The majority of students were comfortable with Twitter and learning to use Twitter likely had minimal negative impact on the other types of interaction.

Vicarious Interaction. Responses to 3 survey questions indicated the potential impact of Twitter as a tool to facilitate vicarious interaction. Responses to question 4 (Table 1 ) indicated that $61 \%$ of students learned something about the course from reading their classmates' tweets. Twenty-four percent of students indicated learning something about the course from guest tweets; however, $53 \%$ indicated not seeing tweets from guests. Similarly, $25 \%$ of students indicated learning something about the course from the instructor's tweets, but $57 \%$ indicated not seeing tweets from the instructor. Vicarious interaction consistently occurred when students read other students' tweets. Students were indifferent on whether they learned something about the course from guests' and/or instructor tweets. However, few students actually saw tweets by guests and/or the instructor.

\section{DISCUSSION}

Twitter usage required approximately 2 hours of planning time, including developing instructions and explaining the activity to the GTAs. In-class time to get student accounts established took longer than expected due to several reasons, including unrealistic expectations by the instructor, the number of students in the course, the tiered lecture layout of the classroom, and the presence of students on 2 separate campuses. A more reasonable expectation would have been 45 minutes.

Even though a Twitter List was used, the most challenging aspect of the activity for GTAs was recording all tweets. Many tools are available to monitor Twitter, but we had not tested them in advance. Ultimately, the GTAs divided up the work of copying tweets from the list into a separate document during class. We took this additional layer of precaution because tweets impacted students' grades; we wanted to be $100 \%$ confident that we had all tweets. Also, this provided a more permanent, accessible copy in the event the instructor wanted to review the tweets in the future. We have since found The Archivist (http://archivist.visitmix.com/) to be a useful tool for tracking tweets.

The majority of students were comfortable using Twitter and were not concerned about their privacy related to its use for the course. In fact, many of the positive comments about students expressing their opinions in class were related to Twitter allowing comments to be anonymous. We did not assess if there would have been an impact on students expressing their opinion if their accounts were public.
The instructor had planned to periodically show tweets in class and integrate them into course discussions. This did not occur frequently because the instructor was not able to decrease the amount of content for each session compared to the previous year. Additionally, the orientation of the teaching station components required the use of a second computer to track tweets. This additional computer increased the number of displays the instructor had to watch to 3, making it difficult to follow the tweet stream. Finally, the volume of tweets on the busier days caused some tweets to appear after the instructor moved to another topic, creating sequencing issues between the content and the tweet stream.

Two features of Twitter present opportunities for distraction when used as a class tool. First, users can send direct, private messages to each other if they know the other person's username. These messages would not be viewable on the list. Ultimately, these private messages are conceptually the same as an e-mail or text message and may present just as much distraction. Second, retweets contain the username of the original person, and when retweeting another person's tweet, the tweet is fully editable. A student could embarrass a classmate by editing their tweet to include inappropriate comments and then retweeting it.

Instructors who are considering using Twitter in a course should critically evaluate the use of hashtags and lists. Both features can be extremely helpful in managing a Twitter activity; however, they do provide distinct features. Using them in tandem may provide the optimal method to allow students, guests, and instructors to participate in the discussion.

Consistent agreement was found among students regarding Twitter use in the course: it was distracting and interfered with note taking. One student suggested that students should have tweeted outside of class when studying or reviewing course materials, allowing them to listen and take notes during class. Students also indicated that the number of tweets to read was overwhelming, likely adding to the sense of distraction. The cognitive complexity learning model provides possible insight into the students' experiences. The model describes a complex, fluid relationship between internal and external information that influences learning. Consistent with the model, students may have experienced a lack of learning time to allow adequate internal processing of stimuli that was being presented from the instructor (lecture content) and/or the activity (tweets). ${ }^{24,25}$ Alternatively, students indicated that Twitter facilitated sharing of ideas, provided an opportunity to learn from classmates' tweets, and allowed them to share opinions when they would not normally have done so. Collectively, student responses 


\section{American Journal of Pharmaceutical Education 2011; 75 (5) Article 88.}

suggest that the activity was distracting but that it also provided value as a social learning tool.

The limitations identified above highlight the primary challenge of the activity: the large number of tweets. Insightful questions were tweeted but never addressed in the tweet stream - by the instructor, guests, or other students. Also, the majority of students reported not seeing instructor and guest tweets. Lastly, the original plan was to periodically show the live tweet stream during class and address interesting tweets that could contribute to the course when they appeared. This rarely happened. Efforts to respond to live tweets should include decreasing the content to cover each day and designating a graduate teaching assistant to monitor the list for tweets to address. According to Kirschner and colleagues, to be meaningful, electronic collaborative learning environments must address learning intentions as soon as they appear. ${ }^{26}$ The volume of tweets and amount of content to be covered each day may have prevented many learning opportunities from being met.

In addition to timely interaction, Kirschner and colleagues indicate that the electronic technology must provide interaction that is meaningful. ${ }^{26}$ Although classified according to the interaction framework, tweets were not assessed for the meaningfulness of the interaction they provided. A review of the tweet transcript identifies some tweets that clearly provided more depth than other tweets (eg, a student's description of their experiences with the day's topic versus a student's tweeting exactly what the instructor said in class). Ways to address this deficit include having a graduate assistant tweet a response to the person who simply typed what the instructor said, designating a group of students to respond to their colleagues' tweets, and decreasing the number of students who tweet each day, which decreases the number of tweets per session, effectively allowing more time for others to respond to the tweets.

Students were asked to indicate yes or no to the statement: "I would like to use Twitter to discuss course content in other classes." Sixty-four percent said no. In survey responses students explained that they viewed Twitter as a distraction from listening and taking notes and that the tweet stream was difficult to follow due to the volume of tweets. Potential remedies to the problems students experienced could include allowing tweets outside of class, increasing the number of "tweetable" days, and grouping students together to tweet with each other. Negative correlations have been found between student achievement and enjoyment of instructional activities under certain circumstances, ie, students may learn more from activities they enjoy less. ${ }^{27}$ Because student preferences may not be an accurate predictor of learning, in- structional practice should be driven by educational goals, available resources, and sound educational models.

\section{SUMMARY}

Instructor, student, and graduate assistant experiences with using Twitter for educational purposes in a large lecture class were reviewed. Students earned a modest amount of points for posting a small number of tweets over a series of class sessions. Students tweeted frequently and consistently. Guests and the instructor tweeted less frequently. Several logistical considerations were identified and addressed, mainly focusing on activity planning and tweet collection. Instructional considerations also were identified and primarily focused on Twitter distracting from listening and taking notes. Students indicated the activity encouraged class participation, allowed them to voice their opinion, and allowed them to share ideas. Instructors considering Twitter use in their course should balance the potential positive aspects of its use with the potentially interruptive nature of Twitter as well as the potentially overwhelming tweet stream that can be generated.

\section{REFERENCES}

1. Oblinger D. Boomers, Gen-xers, and Millennials: understanding the new students. Educause Rev. 2003;38(4):37-47.

2. Gardner SF. Preparing for the nexters. Am J Pharm Educ. 2006;70(4):Article 87.

3. Taylor P, Keeter S. Millennials: a portrait of a generation. Washington, DC: Pew Research Center; 2010 February.

4. Cain J, Fox BI. Web 2.0 and pharmacy education. Am J Pharm Educ. 2009;73(7):Article 120.

5 . Young JR. Forget E-Mail: new messaging service has students and professors atwitter. Chron High Educ. 2008;54(25):A15.

6. Skiba DJ. Nursing education 2.0: Twitter \& tweets. Can you post a nugget of knowledge in 140 characters or less? Nurs Educ Perspect. 2008;29(2):110-112.

7. Kroski E. All a Twitter: Want to try microblogging? Sch Lib J. 2008;54(7):31-35.

8. Dunlap JC, Lowenthal PR. Tweeting the night away: using Twitter to enhance social presence. J Inf Syst Educ. 2009;20(2):129-135.

9. Young JR. Teaching with Twitter: not for the faint of heart. Educ Dig. 2010;75(7):9-12.

10. Stieger S, Burger C. Let's go formative: continuous student ratings with Web 2.0 application Twitter. Cyberpsychol Behav Soc Netw. Apr 2010;13(2):163-167.

11. Billings DM, Kowalski K, Bristol TJ. Twitter: consider the possibilities for continuing nursing education. J Contin Educ Nurs. 2010;41(5):199-200.

12. Bush H. Time to tweet? Hosp Health Netw. 2009;83(6):46,48,51. 13. Eysenbach G. Infodemiology and infoveillance: framework for an emerging set of public health informatics methods to analyze search, communication and publication behavior on the Internet. $J$ Med Internet Res. 2009;11(1): 11.

14. Kaldy J. The social pharmacist: tweeting and posting the way to success. Consult Pharm. 2010;25(1):26-30. 


\section{American Journal of Pharmaceutical Education 2011; 75 (5) Article 88.}

15. Lefebvre C. Integrating cell phones and mobile technologies into public health practice: a social marketing perspective. Health Promot Pract. 2009;10(4):490-494.

16. Scanfeld D, Scanfeld V, Larson EL. Dissemination of health information through social networks: Twitter and antibiotics. $\mathrm{Am} \mathrm{J}$ Infect Control. 2010;38(3):182-188.

17. Vance K, Howe W, Dellavalle RP. Social internet sites as a source of public health information. Dermatol Clin. 2009;27(2):133-136.

18. Fox BI, McDonough SL, McConatha BJ, Marlowe KF.

Technology considerations for establishing and maintaining a satellite campus connected by synchronous video conferencing. Am J Phar Educ 2011;75(5):Article 91.

19. Hillman DC, Willis DJ, Gunawardena CN. Learner-interface interaction in distance education: an extension of contemporary models and strategies for practitioners. Am J Dist Educ. 1994;8(2): $30-42$.

20. Moore MG. Three types of interaction. Am J Dist Educ. 1989;3(2):1-6.
21. Sutton LA. The principle of vicarious interaction in computermediated communications. Int J Educ Telecomm. 2001;7(3):223-242. 22. Twitter. What are hashtags? http://support.twitter.com/entries/ 49309-what-are-hashtags-symbols. Accessed May 12, 2011.

23. Twitter. How to use Twitter lists. http://support.twitter.com/ entries/76460-how-to-use-twitter-lists. Accessed May 12, 2011. 24. Tennyson RD, Rasch M. Linking cognitive learning theory to instructional prescriptions. Instr Sci. 1988;17(4):369-385. 25. Tennyson RD, Breuer K. Psychological foundations for instructional design theory. In: Tennyson RD, Schott F, Seel N, Dijkstra S, eds. Instructional design: International perspectives. Volume 1: Theory, research, and methods. Mahwah, NJ: Lawrence Erlbaum Associates, Inc.; 1997:113-134.

26. Kirschner P, Strijbos J-W, Kreijns K, Beers PJ. Designing electronic collaborative learning environments. Educ Technol Res Dev. 2004;52(3):47-66.

27. Clark RE. Antagonism between achievement and enjoyment in ATI studies. Educ Psychol. 1982;17(2):92-101. 